\title{
Predictors of Response to Repetitive Transcranial Magnetic Stimulation in Depression: A Review of Recent Updates
}

\author{
Sujita Kumar Kar \\ Department of Psychiatry, King George's Medical University, Lucknow, India
}

\begin{abstract}
Transcranial magnetic stimulation (TMS) has been increasingly used in the treatment of various neuropsychiatric disorders including depression over the past two decades. The responses to treatment with TMS are variable as found in the recent studies. Evidences suggest that various factors influence the outcome of depression treated with TMS. Understanding the predictors of response to TMS treatment in depression will guide the clinician in appropriate selection of patients for TMS treatment as well as needful modification in the TMS technique and protocol to have a better clinical outcome. This article comprehensively reviews the factors that predict the outcome of TMS treatment in depression.
\end{abstract}

KEY WORDS: Transcranial magnetic stimulation; Depression; Response; Treatment outcome.

\section{INTRODUCTION}

Transcranial magnetic stimulation (TMS) is a newer brain stimulation technique, which has gained popularity in last three decades. TMS produces magnetic stimulus, which crosses the barrier of scalp, skull and meninges and gets converted to electrical stimulus on the brain surface and modulates the activity of cortical neurons. Repetitive TMS (rTMS) is used for therapeutic purpose in various neuropsychiatric conditions. The frequency of the magnetic stimulus delivered to brain determines, whether the underlying brain structures are stimulated or inhibited. ${ }^{1,2)}$ Low frequency $\mathrm{rTMS}(\leq 1 \mathrm{~Hz})$ has inhibitory effect on the neurons, whereas high frequency $\operatorname{rTMS}(>1 \mathrm{~Hz})$ produces neuronal excitability as well as long term potentiation of neurons. ${ }^{1,2)}$ The rTMS has been used in several clinical trials for management of psychiatric disorders like depression, schizophrenia, obsessive compulsive disorder, substance use disorders, autism spectrum dis-

Received: April 2, 2018 / Revised: May 22, 2018

Accepted: June 14, 2018

Address for correspondence: Sujita Kumar Kar, MD (PSY) Department of Psychiatry, King George's Medical University, Shah Mina Road, Chowk, Lucknow, U.P 226003, India

Tel: +91-9956273747, Fax: +91-522-2265416

E-mail: drsujita@gmail.com

ORCID: https://orcid.org/0000-0003-1107-3021 orders, and eating disorders. ${ }^{1,3-10)}$

Depression is a common neuropsychiatric disorder. Emerging evidences suggest the role of various neuromodulation techniques including TMS in depression. Patients with depression, when treated with TMS, do not show a uniform pattern of response. Variations in the response pattern is attributed to several patient specific, illness specific as well as treatment modality specific factors. It is worthy understanding these factors, that predicts the outcome of depression treated with TMS.

A comprehensive review has been done by reviewing the existing literature on TMS in depression that describes about the predictors of response. Using the keywords "transcranial magnetic stimulation”, "TMS", “Depression”, "predictors of response" in popular search engines (PubMed and Google Scholar) literature were searched till the end of February 2018. All relevant articles (metaanalysis, systematic review, narrative review, original research articles, case reports/series) were evaluated in the review.

\section{TRANSCRANIAL MAGNETIC STIMULATION IN DEPRESSION}

TMS has been approved by US Food and Drug Admin-

(c) This is an Open-Access article distributed under the terms of the Creative Commons Attribution Non-Commercial License (http://creativecommons.org/licenses/by-nc/4.0) which permits unrestricted non-commercial use, distribution, and reproduction in any medium, provided the original work is properly cited. 
istration for use in cases of treatment resistant depression. ${ }^{8)}$ High frequency TMS to the left dorsolateral prefrontal cortex (DLPFC) is recommended for treatment in patients with depression. ${ }^{8}$ The important neurobiologic structures involved in depression are predominantly left DLPFC, hippocampus, subgenual anterior cingulate cortex (ACC) and other limbic structures. Out of these brain structures, subgenual ACC is more specifically involved in depression; but it is deeply seated in the brain and could not be stimulated by TMS. ${ }^{8)}$ The subgenual ACC and DLPFC are having functional connectivity. DLPFC, being located on the cortical surface, is amenable to be modulated by TMS. Hence, left DLPFC is targeted by TMS in depression.

Though there seems to be an anticorrelation between the activity of DLPFC and subgenual ACC, functional neuroimaging studies also give some contradicting findings regarding the connectivity of left DLPFC and subgenual ACC; hence the exact neurobiologic mechanism attributing to antidepressant effect of rTMS over left DLPFC could not be ascertained..$^{8)}$ Consistent evidences support the clinical relevance of two important neuronal circuits (the fronto-parietal central executive network and the medial prefrontal-medial parietal default mode network) in major depression. ${ }^{11)}$ TMS aims these networks for bringing the therapeutic effect.

Most of the existing studies that emphasized on the efficacy of TMS in depression targeted a specific group of population. The populations studied were mostly adult population with treatment resistant depression receiving antidepressant therapy. The therapeutic effect of TMS in these patients might be augmenting effect on the ongoing antidepressants or may be the stand alone effect of TMS. It becomes challenging to predict the efficacy of TMS in depression in the general population by projecting the findings from the specific population studied. So, the findings summarized in this article need to be understood in the light of specific population studied in the individual research works.

\section{rTMS: PREDICTORS OF TREATMENT RESPONSE IN DEPRESSION}

Herrmann and Ebmeier, ${ }^{12)}$ in their review on "factors modifying efficacy of rTMS in depression" of 2006, had raised question regarding the clinical utility of TMS in de- pression and mentioned that there is no specific predictor of TMS efficacy in depression; whatever therapeutic response observed in depression with rTMS is non-specific. However, Centre for Reviews and Dissemination had pointed out some major flaws in selection criteria, possible language bias, inadequacy of methodology and interpretation. ${ }^{12)}$ Various studies concluded about specific factors that can predict the response to TMS in depression. These factors can be broadly understood as patient related factors (e.g., age, gender), illness related factors (i.e., factors related to depression), and TMS procedure related factors (e.g., nature of protocol, site of stimulation).

\section{Patient Related Factors}

Age, gender as well as personality characteristics may have attribution to the therapeutic outcomes in depression treated with TMS. In their study of 2012, Pallanti et $a / .{ }^{13)}$ found that rTMS was having age dependent antidepressant effect; as the age increases, the antidepressant efficacy decreases. There are many possible factors that may attribute to decreased antidepressant effect of rTMS in elderly population, which may be underlying medical condition of the elderly or related to intensity and number of pulses or due to underlying cortical atrophy. ${ }^{14)}$ A recent meta-analysis, which included 54 sham-controlled trials between 1997 and 2013, had revealed that gender might be a positive predictor of response as studies showing good antidepressant response to rTMS had mostly female patients. ${ }^{15)}$ Certain psychological characteristics also predict the response to treatment with rTMS in depression. Siddiqi et al. (2016) $)^{16)}$ had studied "temperament and character inventory" in patients $(n=19)$ receiving rTMS treatment for depression to predict the response. In this study, it was found that high persistence score predicts the response to treatment with rTMS.

In their study of 2006, Fregni et al. ${ }^{17)}$ found that age and treatment refractoriness to be associated with poor antidepressant effect of rTMS and recommended rTMS for patients of younger age and less treatment resistance for a positive outcome. Aguirre et al. $(2011)^{18)}$ found that the efficacy of low-frequency TMS in depression is inversely correlated with age, which emphasizes that younger individuals show better response to TMS. In this study, the patients were highly refractory to treatment, which limits its generalizability. 
The activity of the brain before treatment with TMS may determine the therapeutic outcome. Activity of the brain can be measured through neurophysiological studies and functional neuroimaging. A recent study revealed that patients with better pre-TMS functional connectivity between left DLPFC and striatal connectivity respond better to TMS. Those with better above functional connectivity, show better reduction in depression severity. ${ }^{19)}$ Studies that evaluated the role of functional connections to cerebellum in relation to TMS treatment in depressive disorder, however the findings are not consistent. ${ }^{20)}$ It is found that patients with major depressive disorder with low functional connectivity between cortico-striatal (dorsomedial prefrontal cortex and putamen), corticolimbic and cortico-thalamic connectivity respond better to TMS. ${ }^{20)}$ Philip et al., ${ }^{21)}$ in their study of 2018 , found that at the pretreatment level, a negative functional connectivity between subgenual ACC and default mode network as well as a positive functional connectivity of amygdala with ventromedial prefrontal cortex predicts the treatment response of comorbid depression and posttraumatic stress disorder. In another study, ${ }^{22)} 24$ patients with major depression were treated with high frequency $(10 \mathrm{~Hz})$ rTMS over left DLPFC for two weeks and it was found that having less treatment resistance and high pretreatment ACC volume is associated with better treatment outcome; hence can be considered as positive predictors of antidepressant response to rTMS.

Brain derived neurotrophic factor (BDNF) is a sensitive biological marker of therapeutic efficacy in electroconvulsive therapy; however, its level was found to be unchanged in patients receiving novel non-invasive brain stimulation therapies like rTMS or transcranial direct current stimulation (tDCS), as revealed in a recent systematic review and meta-analysis. ${ }^{23)}$ All the patients $(n=259)$ were having treatment resistant depression and were receiving stimulation over left DLPFC. ${ }^{23)}$ Evidences are inconsistent in predicting the relevance of BDNF with response to TMS. $^{24)}$

Patients, who respond well to TMS, usually have a hyperactive hypothalamo-pituitary-adrenal axis, hence serum cortisol level may predict about the relapse of depressive episode in TMS responders. ${ }^{24)}$ Similarly, the thyroid function test (free T3, free T4, and thyroid stimulating hormone $[\mathrm{TSH}]$ ) was evaluated in patients with depression receiving TMS. ${ }^{24,25)}$ There was no difference in the pre to post intervention free T3 and free T4 levels; however, the TSH level was found high in TMS responders.

\section{Illness Related Factors}

The illness (depression) characteristics may also predict response to treatment with TMS. Nature of depression, severity of the episode and the nature of symptoms may determine the response to TMS treatment. Brakemeier et al., ${ }^{26)}$ in their replication study of 2008 on 79 patients with major depression, evaluated the pattern of response to high frequency rTMS over left DLPFC and found the antidepressant response to be $34.2 \%$ patients only. They also found that patterns of clinical symptoms of depression may predict the rTMS related therapeutic response; depressed mood and guilt feelings being the negative predictors, whereas psychomotor retardation being the positive predictor of response. The cognitive and affective symptoms of depression significantly predict the response to rTMS treatment in comparison to the somatic symptoms. ${ }^{27)}$ Brakemeier et al. $(2007)^{28)}$ concluded that sleep disturbance, low resistance and short episode duration to be the positive predictors of antidepressant effect of rTMS. A recent study ${ }^{27)}$ revealed that there is no difference in the efficacy of rTMS in unipolar depression versus bipolar depression.

It has been also mentioned that patient of depression, who had shown poor response to electroconvulsive therapy, often poorly respond to TMS. ${ }^{29)}$ In a more recent study, Grammer et al. (2015) ${ }^{30)}$ had found that baseline severity of depressive symptoms as a predictor of response. Mild to moderate episodes of depression predict better treatment outcome; duration of treatment and number of TMS sessions carries little significance with regard to the response. Fitzgerald et al. (2016) ${ }^{31)}$ had done analysis of pooled data from 11 different trials of rTMS in depression and found that patients with less severe depressive episode have better response to rTMS. However, another recent naturalistic study revealed that patients with greater severity of depression at baseline respond better to TMS. In this study, the authors had used deep TMS, which has better penetrability than the conventional TMS procedures. ${ }^{32)}$ The authors of this recent study considered that the patients with moderate to severe depression in naturalistic setting were less resistant to medications than the patients who received TMS for depression in other studies, which might be the reason for such 
findings. ${ }^{32)}$ Short duration of the depressive episode and recurrent depressive episodes are also predict a positive response to rTMS treatment. ${ }^{311}$

Patients with depression, who had good response to TMS in their previous depressive episode, also respond to TMS in their subsequent depressive episode. ${ }^{33)}$ Hence earlier good response to TMS can be considered a predictor of response to TMS in depression. TMS mediated stimulation of the left DLPFC result in release of dopamine in the striatum, which might be responsible for the therapeutic effect in depression. ${ }^{19)}$

\section{TMS Procedure Related Factors}

Location of DLPFC stimulation also affects the efficacy of rTMS. As per the standard technique, DLPFC is positioned $5 \mathrm{~cm}$ anterior to the motor cortex across the curvature of scalp. ${ }^{34,35)}$ However, due to anatomical variations in skull size and brain size, this measurement may not be accurate; on the other hand the activation of parts of DLPFC in major depression also varies across patients. ${ }^{8)}$ Inaccurate targeting of DLPFC is like to affect the clinical outcome. Functional neuroimaging or electroencephalography guided DLPFC may improve the clinical outcome. ${ }^{8)}$ Neuronavigation guided TMS is associated with higher amplitude and more stable motor evoked poten-

Table 1. Evidences from studies on repetitive transcranial magnetic stimulation (rTMS) in depression

\begin{tabular}{|c|c|c|c|}
\hline Study & Study sample & Intervention & Predictors of outcome \\
\hline $\begin{array}{l}\text { Baeken et al., } \\
2009^{45)}\end{array}$ & $\begin{array}{l}\text { Antidepressant free, treatment } \\
\text { resistant depression }(n=21)\end{array}$ & $\begin{array}{l}\text { High frequency rTMS over left DLPFC, } \\
10 \text { sessions }\end{array}$ & $\begin{array}{l}\text { High baseline metabolic activities in DLPFC (left) } \\
\text { and high anterior cingulate cortex volume } \\
\text { associated with better outcome }\end{array}$ \\
\hline $\begin{array}{l}\text { Luborzewski } \\
\text { et al., } 2007^{46)}\end{array}$ & $\begin{array}{l}\text { Unipolar major depression } \\
(\mathrm{n}=17)\end{array}$ & $\begin{array}{l}\text { High frequency }(20 \mathrm{~Hz}) \text { rTMS over left } \\
\text { DLPFC, } 10 \text { sessions }\end{array}$ & $\begin{array}{l}\text { Responders had lower baseline level } \\
\text { (pre-treatment) of glutamate than } \\
\text { non-responders }\end{array}$ \\
\hline $\begin{array}{l}\text { Narushima } \\
\text { et al., } 2010^{47)}\end{array}$ & $\begin{array}{l}\text { Patients of medication } \\
\text { resistant vascular depression } \\
(\mathrm{n}=65)\end{array}$ & $\begin{array}{l}\text { High frequency }(10 \mathrm{~Hz}) \text { rTMS over left } \\
\text { DLPFC, } 10 \text { sessions }\end{array}$ & $\begin{array}{l}\text { Increased low theta }(4-5 \mathrm{~Hz}) \text { activity at the } \\
\text { subgenual anterior cingulate cortex is a good } \\
\text { outcome predictor (to rTMS) }\end{array}$ \\
\hline $\begin{array}{l}\text { Langguth et al., } \\
2007^{22)}\end{array}$ & $\begin{array}{l}\text { Patients of major depression } \\
\text { with stable antidepressant } \\
\text { treatment }(n=24)\end{array}$ & $\begin{array}{l}\text { High frequency }(10 \mathrm{~Hz}) \text { rTMS over left } \\
\text { DLPFC, } 2 \text { weeks }\end{array}$ & $\begin{array}{l}\text { High pretreatment (rTMS) regional cerebral blood } \\
\text { flow to anterior cingulate cortex is a good } \\
\text { outcome predictor }\end{array}$ \\
\hline $\begin{array}{l}\text { Fitzgerald et al., } \\
2009^{35)}\end{array}$ & $\begin{array}{l}\text { Patients with treatment } \\
\text { resistant depression }(\mathrm{n}=51) \\
\text { standard } 5 \mathrm{~cm} \text { technique } \\
(\mathrm{n}=27) \text { and neuro-navigation } \\
\text { technique }(\mathrm{n}=24)\end{array}$ & $\begin{array}{l}\text { High frequency }(10 \mathrm{~Hz}) \text { rTMS over left } \\
\text { DLPFC at } 100 \% \text { resting motor } \\
\text { threshold, } 5 \text { days a week for } 3 \text { weeks }\end{array}$ & $\begin{array}{l}\text { At the end of } 4 \text { weeks, patients who received rTMS } \\
\text { by neuro-navigation technique had significant } \\
\text { reduction in depression score in comparison to } \\
\text { those who received rTMS by standard } 5 \mathrm{~cm} \\
\text { technique }\end{array}$ \\
\hline $\begin{array}{l}\text { Herbsman et al., } \\
2009^{34)}\end{array}$ & $\begin{array}{l}\text { Patients with major depressive } \\
\text { disorder }(n=54)\end{array}$ & $\begin{array}{l}\text { High frequency }(10 \mathrm{~Hz}) \text { rTMS over left } \\
\text { DLPFC with a total of } 1,600 \\
\text { pulses/session, } 15 \text { sessions over } 4 \\
\text { weeks }\end{array}$ & $\begin{array}{l}\text { More lateral and anterior placement of TMS coil is } \\
\text { associated with better treatment response }\end{array}$ \\
\hline $\begin{array}{l}\text { Kito et al., } \\
2008^{48)}\end{array}$ & $\begin{array}{l}\text { Patients with treatment } \\
\text { resistant depression }(n=12)\end{array}$ & $\begin{array}{l}\text { High frequency }(10 \mathrm{~Hz}) \text { rTMS over left } \\
\text { DLPFC with a total of 1,000 } \\
\text { pulses/session at } 100 \% \text { resting motor } \\
\text { threshold, } 10 \text { sessions }\end{array}$ & $\begin{array}{l}\text { Increase in regional cerebral blood flow in left } \\
\text { DLPFC, ventrolateral PFC, orbitofrontal cortex, } \\
\text { ACC, left subgenual ACC, anterior insula, right } \\
\text { corpus striatum is associated with antidepressant } \\
\text { effect }\end{array}$ \\
\hline $\begin{array}{l}\text { Kito et al., } \\
2008^{49)}\end{array}$ & $\begin{array}{l}\text { Patients with treatment } \\
\text { resistant depression }(n=14)\end{array}$ & $\begin{array}{l}\text { Low frequency }(1 \mathrm{~Hz}) \text { rTMS over right } \\
\text { DLPFC with a total of } 300 \\
\text { pulses/session, } 12 \text { sessions }\end{array}$ & $\begin{array}{l}\text { Decrease in regional cerebral blood flow in } \\
\text { limbic-paralimbic structures and increased } \\
\text { baseline regional cerebral blood flow in left } \\
\text { hemisphere }\end{array}$ \\
\hline $\begin{array}{l}\text { Kito et al., } \\
2011^{50)}\end{array}$ & $\begin{array}{l}\text { Patients with treatment } \\
\text { resistant depression }(n=26)\end{array}$ & $\begin{array}{l}\text { Low frequency }(1 \mathrm{~Hz}) \text { rTMS over right } \\
\text { DLPFC with a total of } 300 \\
\text { pulses/session, } 12 \text { sessions }\end{array}$ & $\begin{array}{l}\text { Decrease in regional cerebral blood flow in right } \\
\text { PFC, bilateral orbitofrontal corex, right } \\
\text { subgenual ACC is associated with antidepressant } \\
\text { effect of rTMS }\end{array}$ \\
\hline $\begin{array}{l}\text { Kito et al., } \\
2012^{51)}\end{array}$ & $\begin{array}{l}\text { Patients with depression } \\
(\mathrm{n}=24)\end{array}$ & High frequency rTMS over left DLPFC & $\begin{array}{l}\text { Lower is the regional cerebral blood flow ratio bet } \\
\text { ween DLPFC and VMPFC, better is the response } \\
\text { to treatment with high frequency rTMS }\end{array}$ \\
\hline
\end{tabular}

PFC, prefrontal cortex; DLPFC, dorsolateral PFC; ACC, anterior cingulate cortex; VMPFC, ventromedial PFC. 
tials than conventional non-navigated TMS; however, there is no difference in the motor threshold identified through these techniques. ${ }^{36)}$ The accuracy of identifying the motor cortex with neuronavigation assisted TMS is very good. $^{37)}$

A study, used [(18)F]-fluorodeoxyglucose positron emission tomography (PET) and magnetic resonance imaging (MRI) for localizing the target zones on DLPFC for stimulation with rTMS. ${ }^{38)}$ Patients with depression were recruited in three arms; PET-guided, standard and sham. PET-guided TMS is significantly different from sham TMS in terms of therapeutic efficacy; however, there is no significant difference between PET-guided and standard TMS. $^{38)}$

In a randomized, double blind, multicentric study on 301 medication-free patients (155 patients on active TMS group and 146 patients on sham TMS group) suffering from major depressive disorder, high frequency rTMS (10
$\mathrm{Hz})$ at $120 \%$ of motor threshold, 3,000 pulses/session, five days a week for four to six weeks duration was given. ${ }^{39)}$ The outcome in patients receiving active TMS was significantly better in comparison to the group receiving sham TMS. Gross et al., ${ }^{40)}$ in their meta-analysis of 2007, compared the older trials on rTMS with the recent ones and found that the effect size rTMS in depression to be higher in recent studies in comparison to the older ones. More number of rTMS sessions in therapy is associated with better clinical outcome, hence can be considered as a positive predictor of antidepressant response. ${ }^{40)}$ However, it could not be replicated in the subsequent study by Brakemeier et al. ${ }^{26)}$ in 2008, which found that the antidepressant effect of rTMS had significant association with treatment resistance. In a meta-analysis, ${ }^{15)}$ the authors concluded that lesser number of stimuli per session associated with significantly low depression scores and acute antidepressant effect; however, few other con-

Table 2. Predictors of response to rTMS in depression

\begin{tabular}{|c|c|c|}
\hline Predictor & Positive & Negative \\
\hline Neurobiologic & $\begin{array}{l}\text { 1. 5-HT-1a gene polymorphism } \\
\text { 2. LL genotype of the } 5 \text {-HTTLPR gene polymorphism } \\
\text { 32) } \\
\text { 4. } \mathrm{Val} / \mathrm{Val} \text { homozygotes of the BDH, progesterone, estradiol, } \mathrm{TSH}^{52}, \mathrm{BDNF}^{24)}\end{array}$ & \\
\hline Neuroimaging & $\begin{array}{l}\text { 1. Decrease in task related activation of prefrontal cortex } \\
\text { 2. Higher baseline metabolic activities of left DLPFC } \\
\text { 3. High ACC volume } \\
\text { 4. High baseline glucose metabolism at ACC } \\
\text { 5. Lower baseline level (pre-treatment) of glutamate } \\
\text { 6. Decreased metabolism at cerebellum, occipital lobe, anterior } \\
\text { cingulate gyrus and temporal lobe }{ }^{44)} \text { for high frequency TMS } \\
\text { at left DLPFC } \\
\text { 7. Better pre-TMS functional connectivity between left DLPFC } \\
\text { and striatum }^{19)}\end{array}$ & $\begin{array}{l}\text { 1. Higher baseline level (pre-treatment) of } \\
\text { glutamate }^{46)}\end{array}$ \\
\hline Electrophysiologic & $\begin{array}{l}\text { 1. Increased low-theta }(4-5 \mathrm{~Hz}) \text { activity at subgenual } \mathrm{ACC}^{47)} \\
\text { 2. High } \mathrm{APPF}^{54)} \\
\text { 3. Alpha power over parieto-temporal region before treatment }{ }^{55)}\end{array}$ & \\
\hline TMS technique related & $\begin{array}{l}\text { 1. TMS intensity more than } 100 \% \text { of motor threshold }{ }^{31,44)} \\
\text { 2. Number of sessions }>10^{44)} \\
\text { 3. Number of pulses per session }>1,000^{44)}\end{array}$ & \\
\hline Others & $\begin{array}{l}\text { 1. Less severe episode of depression }{ }^{30,31)} \\
\text { 2. History of previous response to } \mathrm{TMS}^{44)} \\
\text { 3. Concomitant antidepressant treatment }{ }^{44)} \\
\text { 4. Short duration of depressive episode } \\
\text { 5. Recurrent depressive episode }>\text { single episode of depression }\end{array}$ & $\begin{array}{l}\text { 1. Short acute treatment }(5-15 \text { sessions) } \\
\text { 2. Drug naive patients (without active } \\
\text { maintenance treatment) } \\
\text { 3. Long duration of the depressive episode }{ }^{44)} \\
\text { 4. Psychotic depression }{ }^{44} \\
\text { 5. Elderly }{ }^{44)} \\
\text { 6. High degree of treatment resistance }{ }^{44,57)}\end{array}$ \\
\hline
\end{tabular}

5-HT, 5-hydroxytryptamine; 5-HTTLPR, serotonin transporter linked polymorphic region; BDNF, brain derived neurotrophic factor; $\mathrm{LH}$, luteinizing hormone; FSH, follicle stimulating hormone; TSH, thyroid stimulating hormone; DLPFC, dorsolateral prefrontal cortex; ACC, anterior cingulate cortex; TMS, transcranial magnetic stimulation; iAPF, individual alpha peak function. 
temporary reviews and meta-analysis disagree with this fact. $^{41,42)}$

Modulation of the excitability of motor cortex prior to delivering high frequency $(10 \mathrm{~Hz})$ rTMS sessions over left DLPFC predicts antidepressant response. ${ }^{43)}$ This study revealed that larger cortico-spinal excitability through motor cortex modulation is associated with better antidepressant effect. ${ }^{43)}$ Choice of laterality (choosing right DLPFC or left DLPFC) for TMS stimulation or bilateral stimulation, does not predict the response in patients with major depressive disorder. ${ }^{44)}$

Table $1^{22,34,35,45-51)}$ summarizes the major studies that predict the response to treatment with TMS in depression. Table $2^{19,24,30,31,44-47,52-57)}$ summarizes various positive and negative predictors of response to TMS treatment in depression.

\section{IMPLICATIONS AND FUTURE DIRECTIONS}

Understanding the predictors of response to TMS treatment in depression will guide the clinicians in appropriate selection of patients for treatment by TMS. It will also sensitize the clinicians to bring modifications in the TMS technique.

Recent evidences suggest that patients after receiving sessions of TMS, show increased level of neurotransmitter $\gamma$-aminobutyric acid (GABA) at the prefrontal cortex. ${ }^{58)}$ Further research is needed to see, whether it can predict the response to TMS. D'Urso et al., ${ }^{59)}$ in their study of 2017 on patients with depression, found that individuals with prominent baseline cognitive disturbances and psychomotor retardation respond better to tDCS. Like tDCS study, these parameters can also be studied in TMS studies in patients with depression, to understand their relevance as predictors of response.

Combination of pharmacotherapy and psychotherapy is often considered as more efficacious than individual strategies alone. Combining TMS with psychotherapy is not thoroughly studied. A recent study reports that simultaneous use of rTMS and psychotherapy is associated high response $(66 \%)$ and remission (56\%) rate. ${ }^{60)}$ The authors concluded that the baseline clinical variables did not predict the response to treatment, however early symptom improvement was highly predictive of response.

Most of the existing studies on rTMS treatment in de- pression are limited by the small sample size. ${ }^{61)}$ Also there are major variations in sample selection, TMS techniques and protocols used as well as parameters of response measured. Overcoming these differences in future research may give better insight to understand the predictors of response.

\section{LIMITATION OF THE CURRENT STUDIES}

Majority of the studies on "rTMS in depression" had excluded psychotic depression, elderly and pediatric population as well as special population like pregnancy. ${ }^{29)}$ Many studies also excluded medical co-morbidities. Though recently, it has been tried in extensively in various other clinical conditions and clinical populations, still the available evidences fall short to predict about the predictors of response to rTMS in depression. Similarly, the findings that predict therapeutic response with TMS in major depressive disorder are not consistent across various studies. The sample sizes of most of the studies that evaluated the predictors of response to TMS, were small and mostly treatment resistant. Hence, study on TMS in more number of patients and clinically diverse population may be more beneficial.

\section{CONCLUSION}

The response to TMS in depression can be predicted. Understanding the predictors of response to TMS treatment in depression will help the clinicians in appropriate selection of patients for TMS treatment and likely to improve to the treatment outcome.

\section{REFERENCES}

1. Mishra BR, Sarkar S, Praharaj SK, Mehta VS, Diwedi S, Nizamie $\mathrm{SH}$. Repetitive transcranial magnetic stimulation in psychiatry. Ann Indian Acad Neurol 2011;14:245-251.

2. Zhang Y, Liang W, Yang S, Dai P, Shen L, Wang C. Repetitive transcranial magnetic stimulation for hallucination in schizophrenia spectrum disorders: a meta-analysis. Neural Regen Res 2013;8:2666-2676.

3. McClelland J, Bozhilova N, Campbell I, Schmidt U. A systematic review of the effects of neuromodulation on eating and body weight: evidence from human and animal studies. Eur Eat Disord Rev 2013;21:436-455.

4. Luigjes J, Breteler R, Vanneste S, de Ridder D. Neuromodulation as an intervention for addiction: overview and future prospects. Tijdschr Psychiatr 2013;55:841-852. 
5. Oberman LM, Enticott PG, Casanova MF, Rotenberg A, Pascual-Leone A, McCracken JT. Transcranial magnetic stimulation in autism spectrum disorder: Challenges, promise, and roadmap for future research. Autism Res 2016;9:184-203.

6. Bais M, Figee M, Denys D. Neuromodulation in obsessivecompulsive disorder. Psychiatr Clin North Am 2014;37:393413.

7. Dougall N, Maayan N, Soares-Weiser K, McDermott LM, Mclntosh A. Transcranial magnetic stimulation for schizophrenia. Schizophr Bull 2015;41:1220-1222.

8. Fox MD, Buckner RL, White MP, Greicius MD, Pascual-Leone A. Efficacy of transcranial magnetic stimulation targets for depression is related to intrinsic functional connectivity with the subgenual cingulate. Biol Psychiatry 2012;72:595-603.

9. Choudhary P, Roy P, Kumar Kar S. Improvement of weight and attitude towards eating behaviour with high frequency rTMS augmentation in anorexia nervosa. Asian / Psychiatr 2017;28:160.

10. Kar SK, Sarkar S. Neuro-stimulation techniques for the management of anxiety disorders: an update. Clin Psychopharmacol Neurosci 2016;14:330-337.

11. Liston C, Chen AC, Zebley BD, Drysdale AT, Gordon R, Leuchter B, et al. Default mode network mechanisms of transcranial magnetic stimulation in depression. Biol Psychiatry 2014; 76:517-526.

12. Herrmann LL, Ebmeier KP. Factors modifying the efficacy of transcranial magnetic stimulation in the treatment of depression: a review. J Clin Psychiatry 2006;67:1870-1876.

13. Pallanti S, Cantisani A, Grassi G, Antonini S, Cecchelli C, Burian J, et al. rTMS age-dependent response in treatment-resistant depressed subjects: a mini-review. CNS Spectr 2012;17:24-30.

14. Sabesan P, Lankappa S, Khalifa N, Krishnan V, Gandhi R, Palaniyappan L. Transcranial magnetic stimulation for geriatric depression: promises and pitfalls. World I Psychiatry 2015;5:170-181.

15. Kedzior KK, Azorina V, Reitz SK. More female patients and fewer stimuli per session are associated with the short-term antidepressant properties of repetitive transcranial magnetic stimulation (rTMS): a meta-analysis of 54 sham-controlled studies published between 1997-2013. Neuropsychiatr Dis Treat 2014;10:727-756.

16. Siddiqi $\mathrm{SH}$, Chockalingam $\mathrm{R}$, Cloninger $\mathrm{CR}$, Lenze $\mathrm{EJ}$, Cristancho P. Use of the temperament and character inventory to predict response to repetitive transcranial magnetic stimulation for major depression. J Psychiatr Pract 2016;22: 193-202.

17. Fregni F, Marcolin MA, Myczkowski M, Amiaz R, Hasey G, Rumi DO, et al. Predictors of antidepressant response in clinical trials of transcranial magnetic stimulation. Int J Neuropsychopharmacol 2006;9:641-654.

18. Aguirre I, Carretero B, Ibarra O, Kuhalainen J, Martínez J, Ferrer A, et al. Age predicts low-frequency transcranial mag- netic stimulation efficacy in major depression. J Affect Disord 2011;130:466-469.

19. Avissar M, Powell F, Ilieva I, Respino M, Gunning FM, Liston $\mathrm{C}$, et al. Functional connectivity of the left DLPFC to striatum predicts treatment response of depression to TMS. Brain Stimul 2017;10:919-925.

20. Dichter GS, Gibbs D, Smoski MJ. A systematic review of relations between resting-state functional-MRI and treatment response in major depressive disorder. J Affect Disord 2015; 172:8-17.

21. Philip NS, Barredo J, van't Wout-Frank M, Tyrka AR, Price LH, Carpenter LL. Network mechanisms of clinical response to transcranial magnetic stimulation in posttraumatic stress disorder and major depressive disorder. Biol Psychiatry 2018; 83:263-272

22. Langguth B, Wiegand R, Kharraz A, Landgrebe M, Marienhagen J, Frick U, et al. Pre-treatment anterior cingulate activity as a predictor of antidepressant response to repetitive transcranial magnetic stimulation (rTMS). Neuro Endocrinol Lett 2007;28: 633-638.

23. Brunoni AR, Baeken C, Machado-Vieira R, Gattaz WF, Vanderhasselt MA. BDNF blood levels after non-invasive brain stimulation interventions in major depressive disorder: a systematic review and meta-analysis. World I Biol Psychiatry 2015; 16:114-122.

24. Fidalgo TM, Morales-Quezada JL, Muzy GS, Chiavetta NM, Mendonca ME, Santana MV, et al. Biological markers in noninvasive brain stimulation trials in major depressive disorder: a systematic review. J ECT 2014;30:47-61.

25. Kito S, Hasegawa T, Fujita K, Koga Y. Changes in hypothalamic-pituitary-thyroid axis following successful treatment with low-frequency right prefrontal transcranial magnetic stimulation in treatment-resistant depression. Psychiatry Res 2010;175:74-77.

26. Brakemeier EL, Wilbertz G, Rodax S, Danker-Hopfe H, Zinka B, Zwanzger $\mathrm{P}$, et al. Patterns of response to repetitive transcranial magnetic stimulation (rTMS) in major depression: replication study in drug-free patients. J Affect Disord 2008;108: 59-70.

27. Rostami R, Kazemi R, Nitsche MA, Gholipour F, Salehinejad MA. Clinical and demographic predictors of response to rTMS treatment in unipolar and bipolar depressive disorders. Clin Neurophysiol 2017;128:1961-1970.

28. Brakemeier EL, Luborzewski A, Danker-Hopfe H, Kathmann $\mathrm{N}$, Bajbouj M. Positive predictors for antidepressive response to prefrontal repetitive transcranial magnetic stimulation (rTMS). J Psychiatr Res 2007;41:395-403.

29. Rachid F, Bertschy G. Safety and efficacy of repetitive transcranial magnetic stimulation in the treatment of depression: a critical appraisal of the last 10 years. Neurophysiol Clin 2006; 36:157-183.

30. Grammer GG, Kuhle AR, Clark CC, Dretsch MN, Williams KA, Cole JT. Severity of depression predicts remission rates us- 
ing transcranial magnetic stimulation. Front Psychiatry 2015; 6:114.

31. Fitzgerald PB, Hoy KE, Anderson RJ, Daskalakis ZJ. A study of the pattern of response to rTMS treatment in depression. Depress Anxiety 2016;33:746-753.

32. Feffer $\mathrm{K}$, Lapidus KAB, Braw $\mathrm{Y}$, Bloch $\mathrm{Y}$, Kron $\mathrm{S}$, Netzer R, et al. Factors associated with response after deep transcranial magnetic stimulation in a real-world clinical setting: Results from the first 40 cases of treatment-resistant depression. Eur Psychiatry 2017;44:61-67.

33. Kelly MS, Bernstein M, Oliveira-Maia AJ, Stern AP, Press DZ, Pascual-Leone A, et al. Response to first course of TMS treatment for depression predicts subsequent response. Brain Stimul 2016;9:e5.

34. Herbsman T, Avery D, Ramsey D, Holtzheimer P, Wadjik C, Hardaway $\mathrm{F}$, et al. More lateral and anterior prefrontal coil location is associated with better repetitive transcranial magnetic stimulation antidepressant response. Biol Psychiatry 2009;66:509-515.

35. Fitzgerald PB, Hoy K, McQueen S, Maller JJ, Herring S, Segrave $\mathrm{R}$, et al. A randomized trial of $r$ TMS targeted with MRI based neuro-navigation in treatment-resistant depression. Neuropsychopharmacology 2009;34:1255-1262.

36. Julkunen P, Säisänen L, Danner N, Niskanen E, Hukkanen T, Mervaala $\mathrm{E}$, et al. Comparison of navigated and non-navigated transcranial magnetic stimulation for motor cortex mapping, motor threshold and motor evoked potentials. Neurolmage 2009;44:790-795.

37. Bashir S, Perez J, Horvath JC, Pascual-Leone A. Differentiation of motor cortical representation of hand muscles by navigated mapping of optimal TMS current directions in healthy subjects. J Clin Neurophysiol 2013;30:390-395.

38. Paillère Martinot $M L$, Galinowski $A$, Ringuenet $D$, Gallarda $T$, Lefaucheur JP, Bellivier $\mathrm{F}$, et al. Influence of prefrontal target region on the efficacy of repetitive transcranial magnetic stimulation in patients with medication-resistant depression: a [(18)F]-fluorodeoxyglucose PET and MRI study. Int / Neuropsychopharmacol 2010;13:45-59.

39. O'Reardon JP, Solvason HB, Janicak PG, Sampson S, Isenberg $\mathrm{KE}, \mathrm{Nahas} \mathrm{Z}$, et al. Efficacy and safety of transcranial magnetic stimulation in the acute treatment of major depression: a multisite randomized controlled trial. Biol Psychiatry 2007;62: 1208-1216.

40. Gross M, Nakamura L, Pascual-Leone A, Fregni F. Has repetitive transcranial magnetic stimulation (rTMS) treatment for depression improved? A systematic review and meta-analysis comparing the recent vs. the earlier rTMS studies. Acta Psychiatr Scand 2007; 116:165-173.

41. Allan CL, Herrmann LL, Ebmeier KP. Transcranial magnetic stimulation in the management of mood disorders. Neuropsychobiology 2011;64:163-169.

42. Berlim MT, Van den Eynde F, Jeff Daskalakis Z. Clinically meaningful efficacy and acceptability of low-frequency repet- itive transcranial magnetic stimulation (rTMS) for treating primary major depression: a meta-analysis of randomized, double-blind and sham-controlled trials. Neuropsychopharmacology 2013;38:543-551.

43. Oliveira-Maia AJ, Press D, Pascual-Leone A. Modulation of motor cortex excitability predicts antidepressant response to prefrontal cortex repetitive transcranial magnetic stimulation. Brain Stimul 2017;10:787-794.

44. Dumas R, Padovani R, Richieri R, Lançon C. [Repetitive transcranial magnetic stimulation in major depression: response factor]. Encephale 2012;38:360-368. French.

45. Baeken C, De Raedt R, Van Hove C, Clerinx P, De Mey J, Bossuyt A. HF-rTMS treatment in medication-resistant melancholic depression: results from 18FDG-PET brain imaging. CNS Spectr 2009; 14:439-448.

46. Luborzewski A, Schubert F, Seifert F, Danker-Hopfe H, Brakemeier EL, Schlattmann P, et al. Metabolic alterations in the dorsolateral prefrontal cortex after treatment with high-frequency repetitive transcranial magnetic stimulation in patients with unipolar major depression. J Psychiatr Res 2007:41:606-615.

47. Narushima K, McCormick LM, Yamada T, Thatcher RW, Robinson RG. Subgenual cingulate theta activity predicts treatment response of repetitive transcranial magnetic stimulation in participants with vascular depression. J Neuropsychiatry Clin Neurosci 2010;22:75-84.

48. Kito S, Fujita K, Koga Y. Changes in regional cerebral blood flow after repetitive transcranial magnetic stimulation of the left dorsolateral prefrontal cortex in treatment-resistant depression. J Neuropsychiatry Clin Neurosci 2008;20:74-80.

49. Kito S, Fujita K, Koga Y. Regional cerebral blood flow changes after low-frequency transcranial magnetic stimulation of the right dorsolateral prefrontal cortex in treatment-resistant depression. Neuropsychobiology 2008;58:29-36.

50. Kito S, Hasegawa T, Koga Y. Neuroanatomical correlates of therapeutic efficacy of low-frequency right prefrontal transcranial magnetic stimulation in treatment-resistant depression. Psychiatry Clin Neurosci 2011;65:175-182.

51. Kito S, Hasegawa T, Koga Y. Cerebral blood flow ratio of the dorsolateral prefrontal cortex to the ventromedial prefrontal cortex as a potential predictor of treatment response to transcranial magnetic stimulation in depression. Brain Stimul 2012;5:547-553.

52. Silverstein WK, Noda Y, Barr MS, Vila-Rodriguez F, Rajji TK, Fitzgerald PB, et al. Neurobiological predictors of response to dorsolateral prefrontal cortex repetitive transcranial magnetic stimulation in depression: a systematic review. Depress Anxiety 2015;32:871-891.

53. Fitzgerald PB, Sritharan A, Daskalakis ZJ, de Castella AR, Kulkarni J, Egan G. A functional magnetic resonance imaging study of the effects of low frequency right prefrontal transcranial magnetic stimulation in depression. J Clin Psychopharmacol 2007;27:488-492. 
54. Arns M, Spronk D, Fitzgerald PB. Potential differential effects of $9 \mathrm{~Hz}$ rTMS and $10 \mathrm{~Hz}$ rTMS in the treatment of depression. Brain Stimul 2010;3:124-126.

55. Micoulaud-Franchi JA, Richieri R, Cermolacce M, Loundou A, Lancon C, Vion-Dury J. Parieto-temporal alpha EEG band power at baseline as a predictor of antidepressant treatment response with repetitive transcranial magnetic stimulation: a preliminary study. J Affect Disord 2012;137:156-160.

56. Kedzior KK, Reitz SK, Azorina V, Loo C. Durability of the antidepressant effect of the high-frequency repetitive transcranial magnetic stimulation (rTMS) in the absence of maintenance treatment in major depression: a systematic review and metaanalysis of 16 double-blind, randomized, sham-controlled trials. Depress Anxiety 2015;32:193-203.

57. Levkovitz Y, Isserles M, Padberg F, Lisanby SH, Bystritsky A, Xia G, et al. Efficacy and safety of deep transcranial magnetic stimulation for major depression: a prospective multicenter randomized controlled trial. World Psychiatry 2015; 14:64-73.

58. Dubin MJ, Mao X, Banerjee S, Goodman Z, Lapidus KA, Kang $\mathrm{G}$, et al. Elevated prefrontal cortex GABA in patients with major depressive disorder after TMS treatment measured with proton magnetic resonance spectroscopy. J Psychiatry Neurosci 2016:41:E37-E45.

59. D’Urso G, Dell'Osso B, Rossi R, Brunoni AR, Bortolomasi M, Ferrucci R, et al. Clinical predictors of acute response to transcranial direct current stimulation (tDCS) in major depression. J Affect Disord 2017;219:25-30.

60. Donse L, Padberg F, Sack AT, Rush AJ, Arns M. Simultaneous rTMS and psychotherapy in major depressive disorder: clinical outcomes and predictors from a large naturalistic study. Brain Stimul 2018;11:337-345.

61. Beuzon G, Timour Q, Saoud M. Predictors of response to repetitive transcranial magnetic stimulation (rTMS) in the treatment of major depressive disorder. Encephale 2017;43:3-9. 